\section{ABORTO E LEGISLAÇÃO COMPARADA}

\author{
José Henrique Rodrigues Torres
}

PARA ONDE DEVEMOS IR? Na atmosfera nonsense do País das Maravilhas (1), quando Alice disse ao gato que não sabia para onde queria ir, ouviu esta óbvia resposta: "Então não importa que caminho tome". Ora, no enfrentamento normativo da questão do aborto, se queremos saber por onde seguir, precisamos saber para onde queremos ir.

Queremos ir na direção de Malta, o país da Uniāo Europeia(UE) com a lei mais restritiva sobre o aborto, onde a interrupção da gravidez é proibida sem nenhuma exceção, considerado um dos mais misóginos do mundo, onde o movimento Gift of Life (Dom da Vida) pretende erigir à preceito constitucional a proibição do aborto, onde o divórcio é proibido e a vida pública é condicionada pela religião de Estado? Ou queremos ir na direção da Holanda, o país dos antípodas europeus dos malteses, onde a decisão sobre a interrupção voluntária da gravidez é tomada pela gestante? (2).

Precisamos decidir aonde queremos ir para escolher as veredas pelas quais devemos caminhar. Mas, como nos adverte o poeta Mario Quintana, serão tristes os caminhos se o caminhar não for iluminado pela mágica presença das estrelas. Assim, para encontrar o caminho correto, é preciso, inicialmente, olhar para os caminhos iluminados pelas experiências vividas pelos demais povos na construção histórica do enfrentamento normativo da questão do aborto.

O CAMINHO PERCORRIDO (3) O que está no interior do útero é um apêndice do corpo da mulher. Era isso o que se pregava até meados do século XVIII. Como dizia o estóico Ulpiano: “mulieris portio vel viscerum".

$\mathrm{Na}$ antiguidade greco-romana, o aborto era moralmente aceito e juridicamente lícito, mas havia um limite: a tutela do interesse masculino, pois o aborto podia contrariar a expectativa do pai, do marido ou do patrão: os gregos não fizeram leis punitivas para o aborto, mas a sua prática exigia a autorização do marido ou patrão, para que não se negasse ao homem a sua descendência; e, em Roma, no século $\mathrm{V}$, a mãe podia ser repudiada pelo marido por subtração de prole.

Depois, no Renascimento, posto que admitida a "contribuição do sangue menstrual para a concepção", prevaleceu a noção da força ativa do esperma e a construção simbólica, funcional e social do corpo da mulher exigia o controle da gestação e do aborto.

$\mathrm{Na}$ segunda metade do século XVIII, embora o meio social e as instituições não se interessassem pelo que ocorria no corpo feminino entre a concepção e o nascimento, o aborto não era livre: era admitido no espaço privado da pobreza, no âmbito da prostituição, ou no âmbito das relações ilícitas ou criminosas, como no adultério, no concubinato e no estupro, "praticados para violar interesses econômicos ou como vingança contra o marido, para privá-lo de sua descendência”. O aborto era reprovado, pois, para preservar os interesses masculinos contra o comportamento devasso das mulheres.
As conquistas científicas ocorridas durante os séculos XVII e XVIII lançaram novas bases sobre essa reflexão, o feto passou a ser considerado como uma entidade autônoma e as afirmações teológicas tiveram eco na legislação civil.

Com a Revolução Francesa e o surgimento dos estados nacionais, as guerras, pestes e descobertas geográficas determinaram novas mudanças: as taxas demográficas diminuíram muito e de modo perigoso para o Estado, que era considerado forte pela quantidade dos seus súditos. Mais filhos para a República significava mais braços empregados no trabalho e na defesa, mais contribuintes e mais soldados para realizar funçōes úteis e necessárias. A vida do indivíduo era interesse do Estado e a maternidade, um ato de patriotismo.

$\mathrm{E}$ as primeiras legislaçôes orgânicas relacionadas ao controle do aborto surgiram na França, em 1870, quando tal ato foi considerado um crime contra a pessoa.

No século XIX, tutelar o feto era uma decisão de Estado, por razôes eminentemente político-ideológicas: a esperança de um futuro cidadão deveria ser preservada, pois "o aborto não lesa a pessoa do nascituro, mas o direito da sociedade ao processo de formação da vida”.

Depois da Primeira Guerra Mundial, já no século XX, as naçôes, levadas pela vaga nacionalista, que pregava a necessidade de famílias numerosas, adotaram sançóes normativas mais severas com relação à contracepção e ao aborto. Nos anos 1940, afirmava-se que o "coitus interruptus defrauda a natureza, exaltando o egoísmo sexual, e o Estado, na medida em que subtrai milhares de cidadãos à nação". O aborto era um "crime contra a integridade e saúde da estirpe", como afirmavam os fascistas. E, na França, em 1942, o aborto era uma ameaça “à segurança interna e externa do Estado", pois produzia "danos ao povo". Obviamente, tais afirmaçōes, normativas inclusive, tinham componentes ideológicos: o crescimento demográfico como condição de desenvolvimento econômico nacional; e o comportamento imperialista para o qual esse aumento é importante na óptica da conquista colonial e do alargamento territorial.

A legislação nazista admitia o aborto, mas não para assegurar direitos às mulheres: o seu objetivo era o aperfeiçoamento da raça; era preciso impedir que as mulheres de raça inferior tivessem filhos; e o aborto, por isso, era incentivado nos territórios ocupados.

Houve uma exceção ao clima repressivo que caracterizou o início do século XX. Em 1920, na Rússia bolchevique, o aborto foi liberado. Contudo, em face do elevado número de infanticídios, uxoricídios e abortos, estes foram proibidos pelo stalinismo. E, em 1936, durante a República Espanhola, com a anarquista Federica Moseny no Ministério da Saúde, legalizou-se o aborto, mas, em 1940, com a implantação do regime franquista, o aborto voltou a ser criminoso.

Depois da Segunda Guerra Mundial, nos anos de 1950 e 1960, em razão do fortalecimento do feminismo e da noção do Estado laico, preparou-se o caminho para que, na Itália, nas décadas seguintes, dois referendos, um sobre o divórcio (1974) e outro sobre o aborto (1981), garantissem a prevalência das escolhas individuais em matéria de foro íntimo e sexual, reconhecendo-se o direito das mulheres à autodeterminação, inclusive quanto ao próprio corpo.

$\mathrm{Na}$ Inglaterra, em 1967, foi aprovado, o Abortion Act. 
Em 1971, 343 mulheres francesas subscreveram um manifesto público, admitindo que haviam praticado o aborto, o que foi determinante para a aprovação, em 1975, da Lei Veil, que legalizou a prática da interrupção voluntária da gestação.

E, no mesmo ano, na Alemanha Ocidental, a revista Stern publicou uma manifestação de 375 mulheres que também admitiram ter praticado o aborto, estimulando mais de 3 mil mulheres a fazerem autodenúncias às autoridades, o que acabou fortalecendo um grande movimento social que, em 1974, possibilitou a legalização do aborto nos primeiros três meses de gestação.

Antes disso, em 1965, depois de uma grande mobilização a favor da legalização do aborto, Colorado e Califórnia, nos EUA, legalizaram o aborto em alguns casos; e, em 1970, Nova Iorque admitiu o aborto com menos de 24 semanas.

Aliás, a legalização do aborto, nos EUA, foi levada à Suprema Corte Americana, que, em 1973, julgando o caso "Roe versus Wade", decidiu que o Estado pode proibir o aborto apenas depois da $24^{\mathrm{a}}$ semana, quando o feto atinge a viabilidade, reconheceu o direito da mulher de escolher interromper ou não a gravidez, como um direito integrador da privacy (liberdade pessoal), garantido pela $14^{\mathrm{a}}$ Emenda da Constituição Americana (4) e afirmou que o feto não é pessoa em termos constitucionais, que existe o direito fundamental ao controle pessoal da capacidade de procriação e que a lei não pode impor a ninguém o sacrifício de si próprio por outra pessoa.

E, apesar das violentas reaçōes contra essa decisão, especialmente do extremista movimento Pro Life, prevaleceu a propensão americana de que os direitos devem ser examinados sob a ótica dos direitos fundamentais e o aborto foi proclamado como uma prática constitucional.

Nos anos 1980, houve várias tentativas, algumas com êxito, para impedir o avanço das ondas da legalização do aborto: na Bélgica, em 1990, o rei recusou-se a ratificar a lei que liberava o aborto; em 1994, na Polônia, o presidente da república, Lech Walesa, também se recusou a assinar a lei que liberalizava largamente o aborto; a Irlanda reconheceu o direito à vida a partir da concepção e afirmou que, "sempre que for aprovada uma lei sobre o aborto, o povo irlandês tem o direito de se opor à aplicação desta no seu território"; e, na Polônia, um movimento cívico que, com mais de um milhão e setecentas mil assinaturas, solicitava a realização de um referendo, foi boicotado por políticos, tribunais e Igreja Católica (5), que, sob o comando do Papa João Paulo II, impulsionou a alteração de uma das leis mais liberais da Europa para uma das mais restritivas.

Na Itália, em 1978, a Lei 194 foi aprovada, permitindo o aborto nos primeiros 90 dias após a concepção para proteger a saúde da mulher (equilíbrio existencial: condiçōes econômicas, sociais e familiares; e previsōes de anomalia ou malformação do nascituro), mas admitindo, também, a objeção de consciência e exigindo aconselhamento médico prévio. Essa lei contrariou a Igreja, que entendeu que estava consagrada a decisão arbitrária da mulher, mas também contrariou o feminismo, porque não se garantiu o princípio da autodeterminação e manteve a criminalização. E essa insatisfação geral levou a Itália, em 1981, a dois referendos, ambos rejeitados: um, ab-rogatório; e o outro, pela total liberalização do aborto.

Como se vê, nos últimos dois séculos, o aborto foi encarado, ora como um assunto masculino, ora como uma questão feminina, mas, como observam Aníbal Faúndes e José Barcelatto (6), nos últimos cinquenta anos, apesar de intensos movimentos reacionários, prevaleceu nos sistemas legais, bem como na esfera da intervenção judicial, a tendência de descriminalização do aborto ou, pelo menos, de ampliação dos casos de autorização para a sua prática.

E, no início do século XXI, ficou assim o panorama normativo do enfrentamento do abortamento na União Europeia:

a) proibição do aborto, sem exceções: Malta;

b) aborto permitido a pedido da mulher, com algum tempo determinado de gestação (de 90 dias a 24 semanas): Reino Unido, Holanda, Suécia, Romênia, Dinamarca, Letônia, República Checa, Eslováquia, Grécia, Hungria, Bélgica, Bulgária, França, Alemanha, Lituânia, Estônia, Portugal, Eslovênia, Áustria e Itália;

c) aborto permitido em razão de risco de vida para a gestante, sempre: Reino Unido, Dinamarca, Suécia, Letônia, Polônia, Eslovênia, Áustria, República Checa, Eslováquia, Romênia, Chipre, Grécia, Hungria, Espanha, Portugal, França, Alemanha, Lituânia, Estônia e Luxemburgo e Irlanda (inclui risco de suicídio);

d) aborto permitido em razão de risco de vida para a gestante, com algum tempo determinado de gestação: Holanda e Finlândia;

e) aborto permitido em razão de risco para a saúde da gestante, sempre: Dinamarca, Eslovênia, Áustria, República Checa, Eslováquia, Romênia, Chipre, Hungria, Bélgica, Itália, França e Alemanha;

f) aborto permitido em razão de risco para a saúde da gestante, com algum tempo determinado de gestação (de 90 dias a 28 semanas): Lituânia, Letônia, Holanda, Reino Unido, Estônia, Irlanda, Luxemburgo, Portugal, Polônia e Espanha;

g) aborto permitido quando a gravidez resulta de estupro ou outro crime sexual, sempre: Romênia, Chipre, Grécia, Alemanha e Hungria;

h) aborto permitido quando a gravidez resulta de estupro ou outro crime sexual, com algum tempo determinado de gestação (de 90 dias a 28 semanas): Dinamarca, Finlândia, França, Espanha, Bélgica, Polônia, Luxemburgo, Portugal, Lituânia, Estônia, Holanda, Letônia e Itália;

i) aborto permitido quando há malformação fetal, sem exigência de tempo de gestação: Reino Unido, Áustria, República Checa, Eslováquia, Romênia, Chipre, Hungria, França, Alemanha e Bulgária;

j) aborto permitido quando há malformação fetal, com algum tempo determinado de gestação: Holanda, Dinamarca, Suécia, Finlândia, Letônia, Polônia, Eslovênia, Grécia, Espanha, Bélgica, Itália, Portugal, Lituânia, Estônia e Luxemburgo; e, finalmente,

k) aborto permitido por razóes socioeconômicas, com algum tempo determinado de gestação: Holanda, Finlândia, Itália, França e Luxemburgo.

Vale destacar Portugal: em 2007, depois de aprovado por referendo popular, o aborto foi autorizado nas seguintes situações: até 
10 semanas de gravidez, a pedido da mulher, independentemente de qualquer motivação; até dezesseis semanas, em caso de estupro ou crime sexual; até 24 semanas em caso de malformação do feto; e, em qualquer momento, em casos de risco para a vida ou para a saúde física ou psíquica da mulher ou nos casos de fetos inviáveis (Lei no 16 , de 17 de abril de 2007). Aliás, a Corte Constitucional Portuguesa, em 1985, já havia decidido que a vida intra-uterina reclama proteção do Estado, mas a Constituição Portuguesa, exatamente como a brasileira, não obriga que essa proteção tenha natureza penal, não sendo possível concluir que "a ausência de proteção penal equivale pura e simplesmente a desamparo e desproteção" (7).

E também é preciso lembrar que, em 2006, o supremo tribunal britânico garantiu o direito das menores de abortar sem o consentimento dos pais (8).

Assim, na UE, apesar de algumas resistências, a tendência está claramente ao lado da legalizaçáo do aborto (9). E o Parlamento Europeu chegou expressamente a incentivar "os Estados-Membros e os países candidatos à adesão a pugnarem pela implementação de uma política de saúde e social que permita uma diminuição do recurso ao aborto e deseja que esta prática seja legalizada, segura e acessível a todos" (10).

E, fora do âmbito da EU, a legalização do aborto no espaço normativo continua avançando no mundo todo: na Austrália o aborto é admitido, embora dependa de autorização médica; no Canadá e na China (11), é legal em todos os aspectos; na Coreia do Norte, admite-se o aborto necessário; no Egito, quando a mulher padece de certas doenças, como câncer ou diabetes; na Índia, a interrupção da gestação é autorizada quando há risco de vida e para a saúde física e mental da mulher, quando a gravidez não é desejada, por estupro ou outros crimes sexuais e, ainda, em razão da situação econômica da gestante, mas não é permitido por simples solicitação; em Israel, permite-se o aborto diante de risco psicológico ou físico para a mulher, nos casos de malformação fetal e, também, o humanitário; no Japão, o aborto é legal até 20 semanas de gestação em casos de malformação fetal, enfermidade mental ou retardamento mental da mulher ou de seu cônjuge, risco de vida para a mulher, estupro e incesto; no México, são admitidos o aborto necessário e o sentimental; e, na Rússia, o aborto é legal e gratuito até três semanas de gravidez.

No sistema interamericano, a jurisprudência afirma que o aborto não viola o direito à vida, ainda que protegido pela Convenção Americana, "em geral", desde a concepção, nos termos de seu artigo $4^{\mathrm{O}}$, endossando, assim, a necessidade de se estabelecer um juízo de ponderação entre os direitos fundamentais da mulher e os direitos de uma vida em potencial (12). Contudo, como observa Estrella Gutiérrez, "a América Latina continua sendo um reduto contra o direito das mulheres decidirem sobre sua gravidez e, apesar de a maioria de seus governantes proclamar-se progressista, apenas em um país o aborto está despenalizado, enquanto em cinco é crime mesmo se a gestação representar risco de vida para a mãe" (13).

Aliás, a Nicarágua, em 2006, escolheu o caminho de Malta e eliminou todas as exceções à criminalização do aborto. E, no Uruguai, em 2008, a legalização do aborto foi aprovada pelos senadores e deputados, fortalecidos pela opinião de pelo menos $63 \%$ dos uruguaios, mas a lei foi vetada pelo presidente Tabaré Vazquez.
Por outro lado, na Colômbia, o Tribunal Constitucional reconheceu, em 2006, três possibilidades em que o aborto deve ser permitido. E no Distrito Federal do México, em 2007, foi legalizado o aborto até 12 semanas de gestação, embora 17 dos 32 estados mexicanos, depois, reagindo àquela legalização, tenham proibido a interrupção voluntária da gestação.

Atualmente, portanto, é esta a situação normativa na América Latina:

a) Cuba, em 1965, legalizou o aborto até 12 semanas de gestação e mantém uma taxa de abortos inferior a 21 para cada mil mulheres em idade reprodutiva, dez pontos abaixo da média regional;

b) Chile, El Salvador, Nicarágua e República Dominicana criminalizam o aborto e não admitem nenhuma exceção (no Chile e em El Salvador, como testemunham Faúndes e Barcelatto, "os médicos realizam abortos para tratamento de gravidez ectópica e ou de câncer do trato genital em mulheres grávidas, sem nenhuma repercussão legal", com base em dispositivos normativos gerais descriminalizadores; mas, no Chile, a lei processual penal determina que os médicos denunciem aos carabineiros o fato de uma mulher apresentar sintomas de ter praticado um aborto, o que os coloca sempre em conflito com direito das pacientes ao sigilo) (14);

c) Honduras, por força de seu Código de Ética Médica, permite o aborto para salvar a vida da gestante;

d) Argentina, Venezuela, Costa Rica, Peru e Paraguai admitem o aborto para salvar a vida da mulher, mas na Argentina também é facultativo o aborto quando a mulher é "idiota ou demente" e, na Venezuela, é permitido, também, para proteger "a honra" da mulher ou do homem; e

e) Uruguai, Colômbia, Equador, Bolívia, México, Panamá e Guatemala permitem o aborto nos casos de violação ou incesto, mas o Uruguai também o admite no caso de "angústia econômica” e a Colômbia, o México e o Panamá, também quando há malformação fetal.

CONCLUSÃO O Brasil mantém a criminalização do aborto, com apenas três exceçōes, duas previstas na lei penal (Código Penal, artigo 128: quando não há outra forma para salvar a vida da gestante e a gravidez resultante de crimes contra a dignidade sexual) e a terceira, admitida em decisōes judiciais (malformação fetal incompatível com a vida extra-uterina).

Todavia, não podemos nos olvidar que o sistema de direitos humanos, positivado no ambiente normativo internacional pelas conferências mundiais, pelos pactos, convençōes, planos e tratados aprovados e ratificados pelo Brasil, bem como pelas recomendações dos comitês da ONU, já reconheceu que as mulheres têm o direito de determinar livremente o número de seus filhos e os intervalos entre seus nascimentos, de decidir sobre o próprio corpo e quanto à maternidade opcional, à plena assistência à saúde sexual e reprodutiva e a uma vida livre da morte materna evitável, à liberdade de autodeterminação, ao controle sobre a sua sexualidade e à livre decisão sobre o exercício da maternidade, sem coerção, discriminação ou violência, e à informação e acesso aos serviços para exercer 
seus direitos e responsabilidades reprodutivas, enquanto os Estados têm o dever, bem como a obrigação ética e jurídica, de assegurar o exercício de todos esses direitos e de garantir às mulheres os direitos à igualdade, à tolerância e à dignidade, de criar condições que assegurem a todas as mulheres a assistência médica plena, especialmente de sua saúde sexual e reprodutiva, de proteger as mulheres dos efeitos negativos à saúde causados pelo abortamento, de eliminar a discriminação contra as mulheres e adolescentes no que diz respeito ao acesso aos serviços de saúde, em todas as fases de seu ciclo de vida, particularmente nas áreas de planejamento familiar, gravidez, parto e pós-parto (15) e, ainda, de assumir o aborto como uma questão de saúde pública, promovendo a exclusão de todas e quaisquer medidas punitivas imposta às mulheres que realizam a interrupção voluntária da gravidez (16), afastando o seu enfrentamento do âmbito do sistema penal, que, em face de seu caráter repressivo, impede que as mulheres tenham o necessário acolhimento no que diz respeito ao exercício material de seu direito à plena assistência sanitária (17), e, finalmente, mantendo um sistema jurídico que garanta a realização do abortamento sem restriçōes, com a garantia de acesso a serviços de alta qualidade para todas as mulheres, independentemente de idade, origem, estado civil ou nível de educação.

Ademais, a Corte Europeia de Direitos Humanos, com base em todos esses princípios e normas, já consolidou o entendimento de que os Estados têm discricionariedade legítima para permitir o abortamento (18), pois, diante da necessária ponderação de bens entre os direitos das mulheres e a proteção do feto (19), devem guiar-se pelo princípio da proporcionalidade, em sua tripla dimensão (adequação, necessidade e proporcionalidade estrita) (20).

Além disso, o Tribunal Constitucional Alemão, invocando o mesmo sistema de proteção dos direitos humanos, decidiu que o legislativo pode estabelecer limites para a realização do aborto, mas não pode criminalizá-lo, assegurando que os direitos constitucionais das mulheres permitem e, em certas hipóteses, exigem a interrupção da gravidez indesejada, com fundamento nos princípios da razoabilidade e da proporcionalidade.

Como se vê, o sistema internacional de direitos humanos é bastante para iluminar o caminho da descriminalização do aborto.

Além disso, também é preciso lembrar que, ao manter a criminalização do aborto, o Brasil viola princípios democráticos elementares relativos à possibilidade de criminalização (idoneidade, subsidiariedade e racionalidade), bem como ignora as exigências jurídico-penais de não se criminalizar uma conduta de modo simbólico ou para impor uma determinada concepção moral ou para punir condutas frequentemente aceitas ou praticadas por parcela significativa da população (21), pois a criminalização do aborto constitui um instrumento ideológico de controle da sexualidade feminina, representa um mero instrumental simbólico da ideologia patriarcal, não tem sido eficaz nem útil para a proteção da vida intra-uterina, está sendo mantida com um enorme custo social, impede a implantação e efetivação de medidas realmente eficazes para o enfrentamento do problema e acarreta às mulheres terríveis sequelas e morte.

Assim, o Brasil, que adotou o sistema democrático e que aderiu a todos os princípios e tratados internacionais de direitos humanos acima referidos (22), incorporando em seu sistema jurídico-constitucional os direitos humanos, sexuais e reprodutivos das mulheres (23), tem a obrigação jurídica e ética de descriminalizar o aborto (24).

Ao contrário de Alice, pois, sabemos para onde devemos ir.

José Henrique Rodrigues Torres é juiz de direito titular da 1a Vara do Júri da Comarca de Campinas, professor de direito penal da Pontificia Universidade Católica de Campinas (Puccamp), especialista em direito das relaçôes sociais e membro da Associação de Juizes para a Democracia.

\section{NOTAS E REFERÊNCIAS BIBLIOGRÁFICAS}

1. Carroll, Lewis. Aventuras de Alice no país das maravilhas \& através do espelho, Edição Comentada por Martin Gardner, Rio de Janeiro: Jorge Zahar. 2002.

2. Cordeiro, Pedro. "Malta e Holanda: os extremos". In: Courrier Internacional, n. 97, p. 14. Lisboa: 9 a 15 de fevereiro de 2007.

3. Galeotti, Giulia. História do aborto. Edições 70, Coimbra: 2003.

4. Toner, Robin, "EUA. Controvérsia consensual". In: Courrier Internacional, p. 15. Lisboa: 9 a 15 de fevereiro de 2007.

5. Chmielewska, Katarzyna, Zukowski Tomasz. "Polônia. Fiasco do movimento pela legalização". In: Courrier Internacional, p. 12. Lisboa: 9 a 15 de fevereiro de 2007.

6. Faúndes, Aníbal, Barcelatto, José. O drama do aborto - em busca de um consenso. Campinas: Komedi. 2004.

7. Diário da República, 2a série, 25.06.1985, p. 254.

8. Donnellan, Ethiene. Irlanda. "Maioria disposta a tolerar". In: Courrier Internacional, p. 13. Lisboa: 9 a 13 de fevereiro de 2007.

9. Piralha, André. "Referendo popular. Leis e lutas". In: Le monde diplomatique - Edição Portuguesa - mensal, n. 3, II, série janeiro/2007, p. 2. Portugal: 11 de fevereiro de 2007.

10. Relatório sobre direitos em matéria de saúde sexual e reprodutiva (2001/2128(INI). Disponível em http://www.europarl.europa. eu/sides/getDoc.do?pubRef=-//EP//TEXT+REPORT+A5-20020223+0+DOC+XML+VO//PT (acesso em 17/11/2007).

11. Chan, Minnie. "China. Obrigadas a abortar".In: Courrier Internacional, p. 15. Lisboa: 9 a 15 de fevereiro de 2007.

12. Convenção Americana sobre Direitos Humanos - Pacto de San José. Disponível em: http://www2.idh.org.br/casdh.htm (acesso em 02/04/2010)

13. Gutiérrez, Estrella. Moeda de pacto e de poder. Caracas: IPS, 2010.

14. Rojas, Carolina. "Chile. Denunciar ou calar?". In: Courrier Internacional, p. 14. Lisboa: 9 a 15 de fevereiro de 2007.

15. Cedaw, $20^{a}$ Session, General recommendations made by the Committee on the Elimination of Discrimination against Women. HYPERLINK "http://www.un.org/womenwatch/daw/cedaw/reporting.htm" Reporting guidelines/ HYPERLINK "http://www.un.org/womenwatch/ daw/cedaw/recommendations/index.html" General recommendations. Cedaw, 20 a Session, General Recommendation n. 24. 1999. Disponível em: http://www.un.org/womenwatch/daw/cedaw/recommendations/recomm.htm (acesso 29/03/2010).

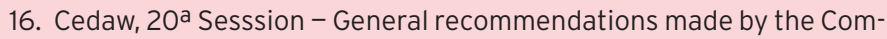
mittee on the Elimination of Discrimination against Women. Reporting 
guidelines / General recommendations. Cedaw, 20 a Session, General Recommendation n. 24. 1999. Disponível em: http://www.un.org/ womenwatch/daw/cedaw/recommendations/recomm.htm (acesso 29/03/2010).

17. Conferência Internacional de População e Desenvolvimento.

18. Ver caso R.H.x Noruega, 1992. RH v. Norway. Decision on admissibility, App. No. 17004/90, Eur. Comm. HR, 19 May 1992.

Disponível em: http://translate.google.com.br/translate?hl=pt-BR\&langpair=en\%7Cpt\&u=http://www.law.georgetown.edu/rossrights/docs/cases/VoComm.pdf. (acesso em 19/03/2010).

19. A respeito, ver caso Vo x França, 2004.

20. A respeito, ver caso Boso x Italia, 2002.

21. Karan, Maria Lucia. "Sistema penal e direitos das mulheres", in Revista Brasileira de Ciências Criminais, n. 9, PP 152 e 153. 2002.

22. Constituição Federal Brasileira, artigo $5^{\circ}$, caput e $\S \S 1^{\circ}, 2^{\circ}$ e $3^{\circ}$ e artigo 60 , parágrafo $4^{\circ}, I V$; Convenção Interamericana para Prevenir, Punir e Erradicar a Violência Contra a Mulher - "Convenção de Belém do Pará", de 1994, ratificada em 27 de novembro de 1995, Convenção Interamericana para Prevenir e Punir Torturas, de 1985, ratificada em 20 de julho de 1989, Convenção Americana de Direitos Humanos - "Pacto de San José da Costa Rica", de 1969, ratificada em 25 de setembro de 1992, Convenção Contra a Tortura e Outros Tratamentos ou Penas Cruéis, Desumanos ou Degradantes, de 1984, ratificada em 28 de setembro de 1989, Convenção sobre a Eliminação de Todas as Formas de Discriminação Contra a Mulher, de 1979, ratificada em $1^{\circ}$ de fevereiro de 1984, Pacto Internacional dos Direitos Civis e Políticos, de1966, ratificado em 24 de janeiro de 1992, Declaração de Pequim, que reconheceu que "os direitos das mulheres são direitos humanos" e que têm as mulheres o direito à plena assistência à saúde sexual e reprodutiva, Conferência Internacional sobre População e Desenvolvimento, realizada em 1994, Conferências Internacionais de Copenhague (Cúpula Mundial de Desenvolvimento Social) e Beijing (IV Conferência Mundial sobre a Mulher, Desenvolvimento e Paz), de 1995, Declaração e Programa de Viena, Pacto Internacional sobre Direitos Econômicos, Sociais e Culturais, Convenção sobre a Eliminação de todas as Formas de Discriminação contra a Mulher (Cedaw), Conferência do Cairo, recomendações do Comitê da Convenção sobre a Eliminação de Todas as Formas de Discriminação contra a Mulher (Cedaw), especialmente artigo 12 dessa Convenção, a Conferência e Plano de Ação de Beijing, capítulo dedicado à Mulher e Saúde, Plano de Ação do Cairo, de 1994, disposições dos Comitês da ONU sobre os Direitos Econômicos, Sociais e Culturais (Pidesc) e sobre a Eliminação da Discriminação contra a Mulher (Cedaw), de 2003, Recomendação Geral n. 19, do Comitê Cedaw, declarações do Comitê Pidesc sobre a criminalização do aborto e recomendações do Comitê de Direitos Humanos da ONU, de 2005, sobre o sistema de proteção dos direitos humanos das mulheres, direitos sexuais e direitos reprodutivos.

23. Piovesan, Flávia. Direitos humanos e o direito constitucional internacional, pg. 83. São Paulo: Max Limonad. 1996.

24. Piovesan, Flávia. "Direitos sexuais e reprodutivos: aborto inseguro como violação aos direitos humanos". In: Nos limites da vida. Rio de Janeiro: Lumen Juris. 2007

\section{BREVE REFLEXÃO GRÍTIGA SOBRE A INGLUSÃo dA temática DO ABORTO NOS CURSOS MÉDIGOS}

\author{
Rosiane Mattar
}

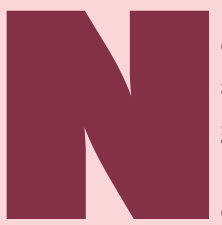

este estudo, propomos uma reflexão crítica sobre a inclusão da temática do aborto nos currículos de graduação médica.

O abortamento espontâneo acontece em 15\% das gestaçōes clinicamente diagnosticadas. Estima-se que o abortamento provocado por razóes socioeconômicas ocorra na frequência de 19 milhões de casos ao ano no mundo. Além deles, devemos contabilizar as interrupçôes de gestações decorrentes de risco de vida para a mãe portadora de patologia grave, as gravidezes resultantes de violência sexual e as interrupçóes realizadas em razão de malformaçôes fetais diagnosticadas no decorrer da prenhez.

Assim, podemos notar que o abortamento é o evento mais frequente da obstetrícia.

Há que se considerar ainda que o abortamento representa, nos países em desenvolvimento, a terceira ou quarta causa de morte materna além de ser importante causa de morbidade para a mulher que, muitas vezes, sofre a perda de seus órgãos reprodutores (1).

No Brasil, 250 mil internações/ano no Sistema Único de Saúde (SUS) são consequentes a abortos clandestinos com intercorrências. O aborto clandestino é a terceira causa de morte materna no Brasil, ceifando vidas das mulheres mais pobres.

Considerando a frequência e a importância dos agravos que o aborto pode determinar é justo pensar que este tema deveria ser abordado de maneira absolutamente completa e sem preconceito nos cursos de graduação de medicina, enfermagem e de outros profissionais afeitos aos cuidados com a saúde integral da mulher. Quando falamos de forma completa, entende-se que não somente fossem analisados temas como a etiologia, diagnóstico, quadro clínico e tratamento, mas também aspectos emocionais ligados à perda da gravidez ou à decisão de interrompê-la, os aspectos sociais e legais ligados à interrupção da gestação, a responsabilidade da decisão, a obrigação dos órgãos governamentais, a solidão em que as mulheres são colocadas nessas situaçôes.

Entretanto, o que percebemos, até o momento, é que se garante mais tempo dentro dos currículos para doenças absolutamente raras em frequência ou com repercussões não tão graves, ao mesmo tempo em que se nota grande dificuldade em que este tema seja amplamente discutido na graduação.

Reforça-se aqui o paradigma cartesiano da doença, sem levar em conta as diferentes histórias de vida das mulheres. Uma série de razōes pode ser aventada para essa dificuldade. Primeiramente, a interrupção da gravidez é um tabu social e existe grande constrangimento entre os professores e uma grande dificuldade de discutir esse tema com os estudantes. Muitos professores não têm opinião formada sobre ele, ou mesmo se negam a dar importância ao assunto. 